\title{
Virulence Genes of the Phytopathogen Rhodococcus fascians Show Specific Spatial and Temporal Expression Patterns During Plant Infection
}

\author{
Karen Cornelis, ${ }^{1,2}$ Tania Maes, ${ }^{1}$ Mondher Jaziri, ${ }^{2}$ Marcelle Holsters, ${ }^{1}$ and Koen Goethals ${ }^{1}$ \\ ${ }^{1}$ Vakgroep Moleculaire Genetica, Departement Plantengenetica, Vlaams Interuniversitair Instituut voor Biotechnologie \\ (VIB), Universiteit Gent, K.L. Ledeganckstraat 35, B-9000 Gent, Belgium; ${ }^{2}$ Laboratoire de Biotechnologie Végétale, \\ Université Libre de Bruxelles, Chaussée de Wavre 1850, B-1160 Brussels, Belgium
}

Submitted 19 July 2001. Accepted 24 December 2001.

\begin{abstract}
The phytopathogenic bacterium Rhodococcus fascians provokes shoot meristem formation and malformations on aerial plant parts, mainly at the axils. The interaction is accompanied by bacterial colonization of the plant surface and tissues. Upon infection, the two bacterial loci required for full virulence, fas and att, were expressed only at the sites of symptom development, although their expression profiles differed both spatially and temporally. The att locus was expressed principally in bacteria located on the plant surface at early stages of infection. Expression of the fas locus occurred throughout infection, mainly in bacteria that were penetrating, or had penetrated, the plant tissues and coincided with sites of meristem initiation and proliferation. The implications for the regulation of virulence genes of $\boldsymbol{R}$. fascians during plant infection are discussed.
\end{abstract}

Additional keywords: GUS fusion, histochemical analysis.

The gram-positive bacterium Rhodococcus fascians causes witches' broom and leafy gall formation on a wide variety of plant species (Goethals et al. 2001; Vereecke et al. 2000). Leafy galls consist of compact masses of meristematic tissues that are covered with small shoots. When tobacco (Nicotiana tabacum L.) plants are dipped in a bacterial suspension, leafy galls are formed at the axils and on the veins of some leaves. These galls originate from the proliferation of both existing and newly induced shoot meristems (de O. Manes et al. 2001; Vereecke et al. 2000).

The pathogenicity of $R$. fascians strain D188 is correlated with a linear plasmid, pFiD188, on which several virulence loci have been identified (Crespi et al. 1992). The fas operon is involved presumably in the biosynthesis of a cytokininlike molecule, and mutation of this locus results in a nonpathogenic strain (Crespi et al. 1994; Temmerman 2000). Expression of the fas locus in batch cultures is controlled by the fas $R$ gene and is posttranscriptionally induced by extracts of infected

Corresponding author: M. Holsters; Fax: +32 9 2645349; E-mail: mahol@gengenp.rug.ac.be

Current address of K. Cornelis: Entwicklungsgenetik, Universität Tübingen, Auf der Morgenstelle 3, D-72076 Tübingen, Germany.

Current address of T. Maes: Department of Respiratory Diseases, Universitair Ziekenhuis, De Pintelaan 185, B-9000 Gent, Belgium. plants when certain conditions regarding cell density and nutritional status are met (Temmerman et al. 2000).

Mutation of the att locus results in strains with reduced virulence (Crespi et al. 1992; Maes et al. 2001). The att operon is involved in the biosynthesis of regulatory compounds that are necessary to induce att and fas gene expression and are produced during the interaction with the plant (Maes et al. 2001). The transcription of the att genes and the induction of fas gene expression in batch cultures are controlled by the regulatory attR gene. attR mutants cause weak and variable symptoms (Maes et al. 2001; D. Vereecke, unpublished data).

Previously, we examined the infection behavior of $R$. fascians on plants in a gnotobiotic system and found extensive colonization both on the surface and in the plant tissues without a necessary association to symptom development. Bacteria penetrated the plant tissues through ingression sites and were mainly intercellular, although putative intracellular bacteria could be observed (Cornelis et al. 2001).

The spatial and temporal expression patterns of the $R$. fascians virulence genes during plant surface and tissue colonization were unknown. Therefore, $R$. fascians strains harboring $\beta$ glucuronidase (uidA) fusions were used to investigate fas and att expression during the infection of tobacco plants.

\section{RESULTS}

Expression of the fas and att loci during plant infection was investigated through the $\beta$-glucuronidase (GUS) activity of $R$. fascians D188 strains that carried translational or transcriptional fusions of the respective promoter and the Escherichia coli gene encoding $\beta$-glucuronidase (uidA) on a replicating plasmid (Table 1). Plasmid stability during infection was confirmed by colony counting on nonselective and selective media for at least 3 weeks after inoculation (data not shown).

\section{The fas and att genes are expressed}

in bacteria located at axils.

To obtain an overview of the expression patterns of the fas and att loci during infection, the GUS activity on different aerial plant parts was determined by staining complete plants. This activity was examined visually 3,7 , and 14 days after tobacco plants had been dipped into suspensions of different $R$. fascians D188 strains. With strain D188[pRFWT11], which harbors a transcriptional fas-uidA fusion, no GUS staining was detected at any time point; whereas with strain D188[pJDGV5], 
which carries a translational fas-uidA fusion, GUS activity was found to be located at the axils, leaves, and stem. Significantly more plants showed GUS staining at the axils than on the leaves and stem (69 to $78 \%$ versus 6 to $22 \%$, respectively; $P<$ $0.005 ; 40$ plants per time point). This activity was maintained for 14 days after inoculation (Fig. 1E). At later time points, strong GUS activity was associated with small shoots that emerged from the axils (Fig. 1I).

GUS staining on plants infected with $R$. fascians strains with transcriptional or translational att-uidA fusions (D188[pRFTM2] and D188[pRFTM3], respectively), occurred more frequently at the axils (64 to $70 \%$ ) than on the stem or leaves (7 to $20 \%$ ) until 7 days postinoculation $(P<0.01$ for 3 and 7 days of infection; 45 plants per time point). At 14 days after inoculation, the staining was diffuse on the shooty outgrowths and did not differ significantly between the different plant parts. At later time points, the activity of the att-uidA fusions resulted in a dispersed and weak staining.

The localized staining of bacteria at the axils that harbor either a fas-uidA or att-uidA fusion could be due to a locally larger bacterial population, an increased expression of the fusions at these sites, or both. Therefore, GUS activity on different plant parts was quantified in relation to the number of colonyforming units (CFU) (Fig. 2). At inoculation, no GUS activity was detected with any of the strains. The GUS activity per CFU after inoculation with D188[pJGDV5] (translational fasuidA fusion) was significantly higher at the axils than on the leaves at all time points $\left(\mathrm{F}_{(1,153)}=29.4, P<0.001\right.$; Fig. $2 \mathrm{~A}, 30$ plants examined per time point), but decreased from day 3 to 7 after inoculation and remained the same afterward. On the leaves, the activity did not change significantly between the different time points (Fig. 2A).

Overall, the GUS activity per CFU for strains D188[pRFTM2] and D188[pRFTM3] was 10-fold higher than that of the fas fusion. Initially, expression of the att-uidA fusions followed the pattern of the fas fusion, with the GUS activity per CFU being significantly lower on the leaves than that at the axils $\left(\mathrm{F}_{(1,59)}=\right.$ 23.1 and $P<0.005$ and $\mathrm{F}_{(1,59)}=30.8$ and $P<0.001$ at 3 and 7 days, respectively; Fig. $2 \mathrm{~B}$ and $\mathrm{C}$ ). At each time point, 30 plants were examined. With time, the level of GUS activity per CFU of the att fusions decreased at the axils, so that 14 days after inoculation, the expression levels on the leaves and at the axils did not differ significantly. At the various time points, no alterations in the GUS activity level were observed on the leaves.

In cultures, expression of the fas locus requires the presence of the regulatory genes fas $R$ and $a t t R$. fas $R$ mutants are nonvirulent, whereas att $R$ mutants cause weak and variable symptoms (Maes et al. 2001; Temmerman et al. 2000). During symptom development, the involvement of attR in fas gene expression was assessed by quantifying the GUS activity on the leaves and at the axils upon inoculation with the attR mutant strain D188- $\triangle a t t R$ [pJDGV5], which carries the translational fas-uidA fusion (Fig. 2A). At days 3 and 7 after inoculation, fas expression was low, but after 14 days at the axils, it reached a level similar to that in wild-type bacteria (Fig. 2A, 25 plants examined per time point). Thus, the attR gene is required for fas expression during early infection only.

The number of CFU/g of plant tissue did not differ whether recovered from the axils or the leaves $\left( \pm 10^{6} \mathrm{CFU} / \mathrm{g}\right.$ and $10^{7}$ $\mathrm{CFU} / \mathrm{g}$ of plant tissue after 1 and 2 weeks, respectively). Thus, variations in bacterial density are not the cause of the observed spatial differences in virulence gene expression levels.

\section{Microscopic analysis of $f$ as and att expression at the axils.}

Semithin sections were analyzed for GUS staining by light microscopy (described below) to evaluate the occurrence of fas- and att-expressing bacteria in axil tissues. Some sections were stained with toluidine blue for morphological examination. A previously described in situ hybridization technique (ISH) (Cornelis et al. 2001) could not be used to simultaneously monitor bacterial colonization on these sections because of differences in fixation requirements. Immunolocalization (IL) with a polyclonal antibody raised against $R$. fascians cells (described below) proved to be compatible with the GUS assay procedure. However, ISH and GUS assays revealed more bacteria inside the plant tissues than did IL (compare Fig. 1D and $\mathrm{C}$, where bacteria detected by IL are visualized in green and those expressing a fas-GUS fusion in red, respectively), making the IL method mainly suited for visualizing surface-located bacterial populations.

Expression of the fas locus, as monitored with D188[pJDGV5], occurred at the axillary meristems, at the newly formed meristematic areas, and at the outgrowing shoot primordia (Fig. 1A to J). At day 3 after infection, GUS staining was observed on the plant surface and inside the tissues (Fig. $1 \mathrm{~A}$ to $\mathrm{C}$ ), and at later time points, fas was primarily expressed in bacteria inside the plant (Fig. $1 \mathrm{~F}$ to $\mathrm{H}$ and $\mathrm{J}$ ). At day 3 after inoculation, expression of fas was observed in the epidermal cell layers, facing newly formed meristem initials in the parenchyma (Fig. 1F). Proliferating meristems developed subsequently into shoot primordia, and fas expression was detected throughout these newly initiated shoots. Later, fas expression was colocalized with the meristematic zone of the shoot primordium (Fig. $1 \mathrm{~J})$. When primordia developed into misshapen shoots, the GUS staining remained at the base of these outgrowths (Fig. 1I). At all time points, IL showed the presence of surface-located bacteria that did not express the fas locus (Fig. 1C and D).

Expression of the att-uidA fusions in strains D188[pRFTM2] and D188[pRFTM3] was detected only on the plant surface and was absent in bacteria that had penetrated the plant tissues (Fig. 1L). At 3 and 7 days after inoculation, the att locus was expressed in bacteria on the plant surface, facing the sites in the parenchyma where meristem initials were formed. At later stages, when shoot primordia proliferated, the GUS staining was weak and not restricted to a specific zone, as seen for fas expression. From the IL analysis, only a subpopulation of the

Table 1. Plasmids of Rhodococcus fascians strain D188

\begin{tabular}{|c|c|c|c|}
\hline Plasmid & Antibiotic resistance $^{a}$ & Description & Reference \\
\hline pRF37 & Amp, Phleo & Bifunctional cloning vector that replicates in both Escherichia coli and $R$. fascians & Desomer et al. (1992) \\
\hline pRFWT11 & Amp, $\mathrm{Cm}$ & $\begin{array}{l}\text { Replicating plasmid (pRF37) with a transcriptional fusion of the upstream region of } \\
\text { the fas operon to the uidA gene }\end{array}$ & Temmerman et al. (2000) \\
\hline pJDGV5 & Amp, $\mathrm{Cm}$ & $\begin{array}{l}\text { Replicating plasmid (pRF37) with a translational fusion of the upstream region of } \\
\text { the fas operon to the uidA gene }\end{array}$ & Temmerman et al. (2000) \\
\hline pRFTM2 & Amp, Phleo & $\begin{array}{l}\text { Replicating plasmid (pRF37) with a transcriptional fusion of the upstream region of } \\
\text { the att operon to the uidA gene }\end{array}$ & Maes et al. (2001) \\
\hline pRFTM3 & Amp, Phleo & $\begin{array}{l}\text { Replicating plasmid (pRF37) with a translational fusion of the upstream region of } \\
\text { the att operon to the uidA gene }\end{array}$ & Maes et al. (2001) \\
\hline
\end{tabular}

\footnotetext{
${ }^{\mathrm{a}} \mathrm{Amp}=$ ampicillin, $\mathrm{Cm}=$ chloramphenicol , and $\mathrm{Phleo}=$ phleomycin.
} 
bacteria present on the plant surface expressed the att locus at all time points (data not shown).

Possible causes of the reduced detection of bacteria inside the plant tissues when IL was compared with ISH could be a penetration problem of the antibody into the plant tissues or a severely reduced availability of the epitopes detected by the antibodies. To distinguish between these two possibilities, IL was performed on extracts of infected plants-eliminating possible penetration problems - and the number of detected bacteria was compared with that stained with 4',6-diamidino-2phenylindole (DAPI). The percentage of bacteria detected by IL was $95 \%( \pm 5 \%)$ from batch cultures and $70 \%( \pm 13 \%)$ from extracts of infected plants that had not been surface-sterilized.
After the plants had been surface-sterilized and washed extensively, only $20 \%( \pm 15 \%)$ of the extracted bacteria were detected by IL when compared with the number found by DAPI staining. Similar results were obtained when IL was compared with ISH (data not shown), suggesting that free-living and plant surface-located bacteria differ in epitope presence or availability when compared with bacteria that reside in the plant.

\section{DISCUSSION}

To better understand the regulation and role of the fas and att genes during the $R$. fascians-tobacco interaction, we studied the expression profiles of $R$. fascians strains carrying different
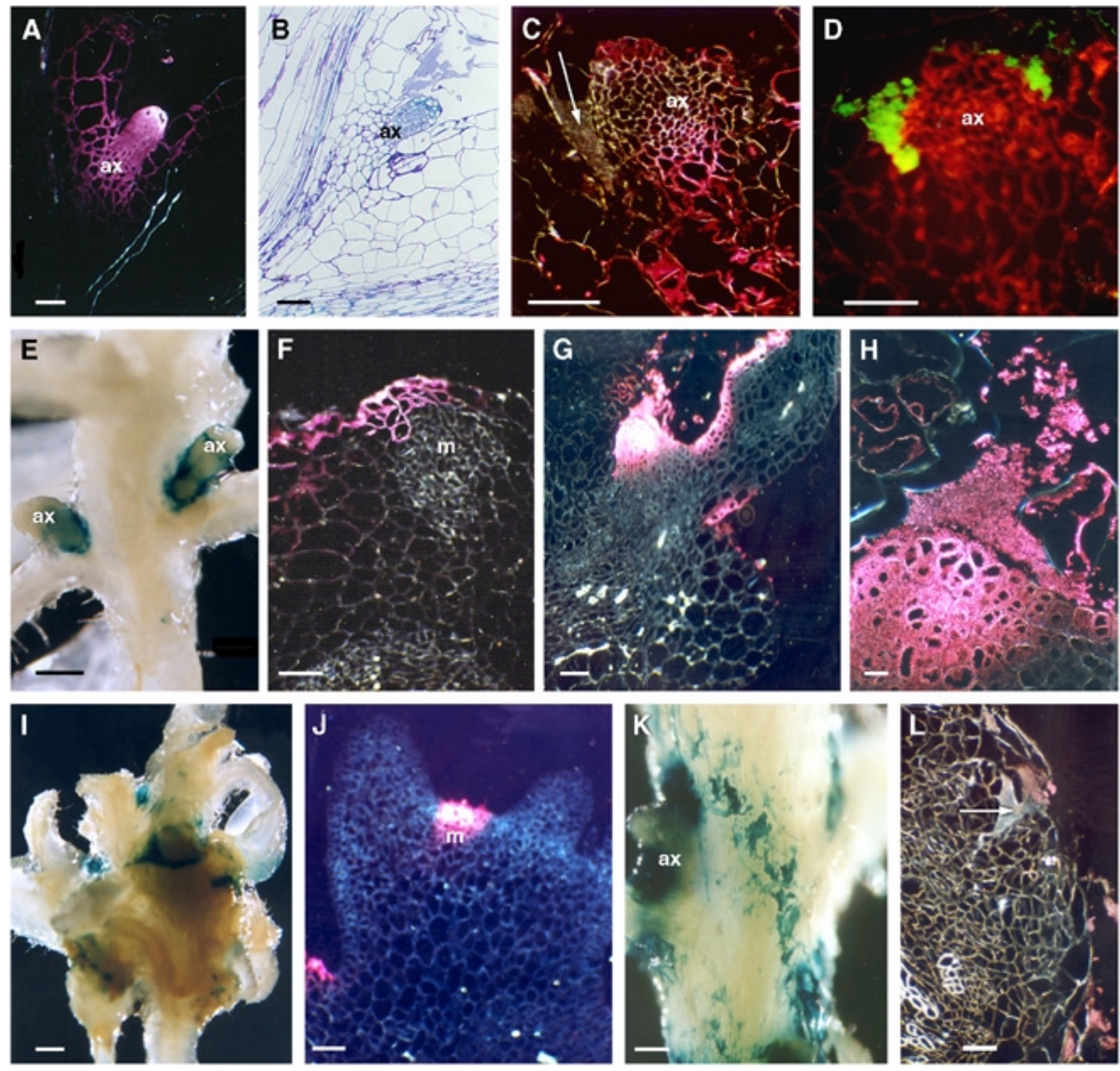

Fig. 1. Expression of the $\mathbf{A}$ to $\mathbf{J}$, fas and $\mathbf{K}$ and $\mathbf{L}$, att loci at the axils of infected tobacco plants. GUS activity was visualized as $\mathbf{A}, \mathbf{C}, \mathbf{F}$ to $\mathbf{H}, \mathbf{J}$, and $\mathbf{L}$, dark-field and $\mathbf{E}$, I, and $\mathbf{K}$, binocular images. A and B, Longitudinal sections through axils 3 days after infection. B, Semiadjacent toluidine blue-stained section of A. C and D, Longitudinal section through the axillary meristem 3 days after infection. D, Rhodococcus fascians detected by immunolocalization (green color corresponds to fluorescein isothiocyanate isomer I-conjugated secondary antibody). E, Stem and axils of a tobacco plant 7 days after infection. F, Transversal section through a stem with a developing meristematic area 7 days after infection. G, Section at the axil through a protruding outgrowth 14 days after infection. H, Enlargement of G. I, Leafy gall cut through the middle 21 days after infection. J, Section through a small shoot apex from a leafy gall 21 days after infection. K, Part of the stem of a tobacco plant 3 days after infection with strain D188[pRFTM2]. L, Transversal section through an ingression site on the stem 7 days after infection with strain D188[pRFTM2]. ax = Axillary meristem, and $\mathrm{m}=$ meristem. $\mathbf{C}$ and $\mathbf{L}$, Arrows indicate groups of bacteria not expressing GUS. E, I, and K, Bars = $1 \mathrm{~mm}$. A to D, F, G, J, and L, Bars = $100 \mu \mathrm{m}$. H, Bar $=10 \mu \mathrm{m}$. 
GUS fusions inoculated onto plants. Virulence gene expression occurred mainly at the sites of symptom development. However, the expression profiles of the fas and att genes differed both spatially and temporally. The att locus was expressed principally in bacteria located on the plant surface at early stages of infection. Expression of the fas locus occurred throughout infection, mainly in bacteria that were penetrating, or had penetrated, the plant tissues and coincided with sites of meristem initiation and proliferation. Thus, the bacterial population on a plant is not homogeneous in terms of virulence gene expression. This finding is reinforced by the fact that epitopes for antibody binding seem to be altered in bacteria in plants when compared with free-living or surface-located bacteria.

The fas locus is involved in the synthesis of a cytokininlike signal molecule (Crespi et al. 1992; Temmerman 2000). Expression of the fas genes in bacteria located in the epidermis coincides with the dedifferentiation of parenchyma cells to shoot meristems, suggesting that the signal does not need to be produced directly at the target parenchyma cells. Formation of the shoot primordia is correlated with fas expression in bacteria located in the meristematic centers. Because the fas expression is maintained throughout symptom development, the formation and amplification of these primordia relies on a constant supply of the fas signal molecules by the bacteria.

The att locus is implicated in the production of compounds that are necessary for the induced expression of the att and fas genes (Goethals et al. 2001; Maes et al. 2001). During the first week of inoculation, att expression is highest at the axils, conceivably leading to higher levels of inducer at these locations. This observation could account for the elevated expression of the fas locus in bacteria at axils when compared with that in leaves or stems, thus causing symptom development at these sites. The lower att expression level on the leaves might result in an insufficient level of inducer.

The regulated expression of virulence genes in $R$. fascians could be influenced by conditions specific for the axils that might represent the initial requirement for an up regulation of att gene expression. Positive autoregulation of the att genes may subsequently lead to a sufficient accumulation of inducer and consequent expression of the fas locus.

The initial factors that enhance att expression at the axils are unknown. By analogy with plant-secreted substances that
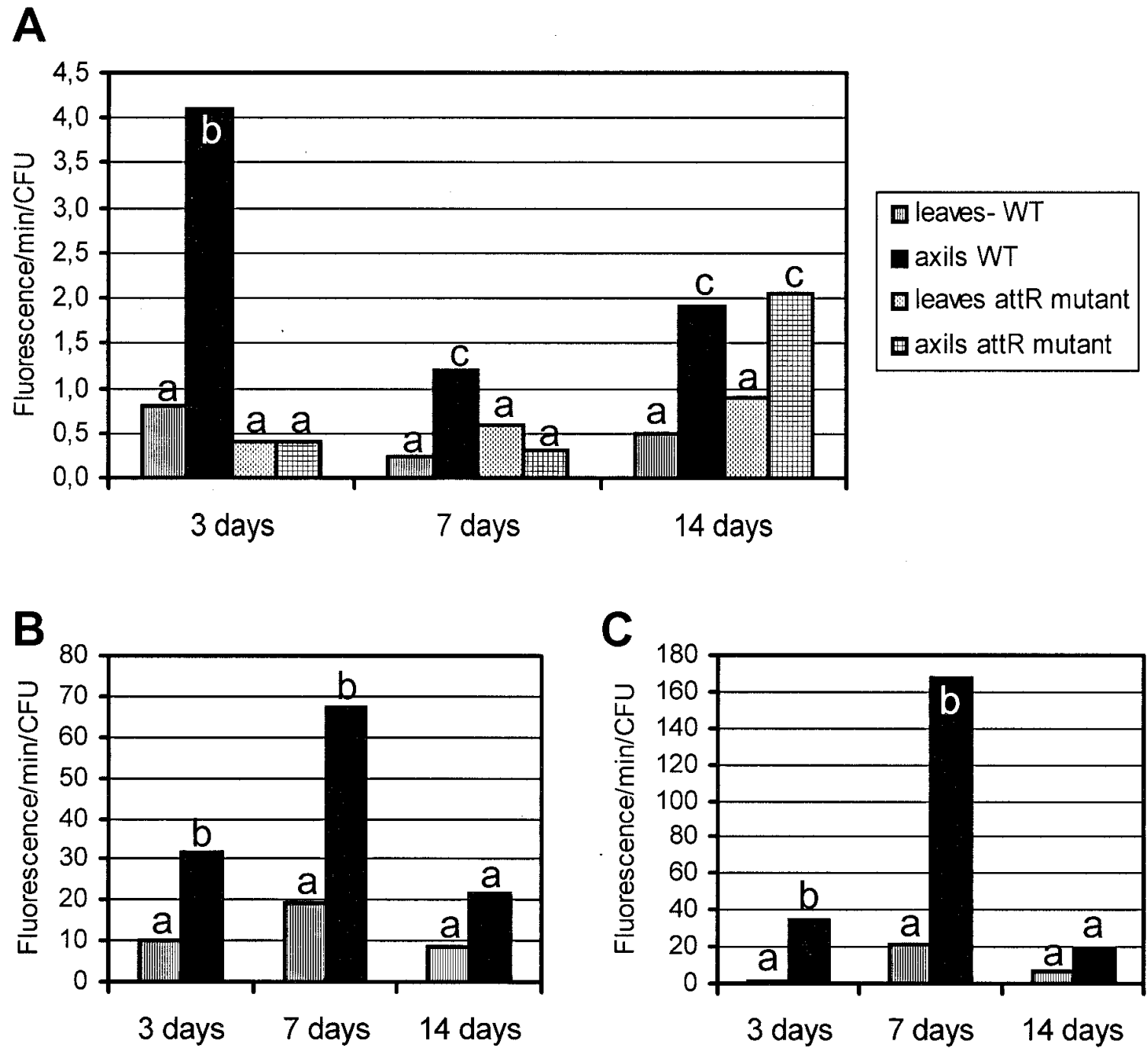

m leaves axils

Fig. 2. Quantification of GUS activity per CFU of bacteria at the axils or on the leaves of infected tobacco plants at different time points after infection. Each group consists of measurements on 30 plants. A, GUS activity derived from pJDGV5 in wild-type bacteria and in strain D188- $\Delta a t t R$. B, GUS activity derived from wild-type bacteria. C, GUS activity derived from pRFTM3 in wild-type bacteria. In each graph, groups that are indicated with the same letter are not significantly different from each other $(P<0.01)$. 
mimic bacterial autoinducing compounds (Teplitski et al. 2000), specific plant-derived compounds with a higher local concentration at the axils might be sufficient to enhance att expression. The signals could also be of bacterial origin as with quorum sensing in gram-negative bacteria, in which acetylated homoserine lactones regulate gene expression in a cell densitydependent manner (Fuqua et al. 1994, 1996). Also in grampositive bacteria, a variety of compounds act as signaling molecules for gene regulation in a cell density- or growth phase-dependent manner (Dunny and Leonard 1997; Horinouchi and Beppu 1992; Kleerebezem et al. 1997). Several virulence genes in Ralstonia solanacearum are regulated by a bacterial fatty acid molecule that acts as a confinement signal (Schell 2000). Expression of the fas gene increases at high cell densities in batch cultures (Temmerman et al. 2000), but the bacterial density at the axils is similar to that at other plant parts and att induction by gall extract in batch cultures could not be mimicked by high bacterial cell densities (Maes et al. 2001). Thus, additional conditions may be required, including the environment in a particular niche and the bacterial metabolic state.

The fas locus is expressed mainly in bacteria residing inside the plant, whereas att expression is restricted to bacteria on the plant surface, resulting in only a small spatial overlap of expression patterns. Upon penetration of plant tissues, the bacteria encounter conditions that differ from those at the plant surface. Conceivably, besides the inducer synthesized through the att locus, expression of fas requires additional conditions. In batch cultures, the expression of fas is more tightly regulated than that of att and is strongly influenced by $\mathrm{pH}$, with an optimal induction at pH 5 (Maes et al. 2001; Temmerman et al. 2000), which is approximately the $\mathrm{pH}$ of the plant apoplast (Grignon and Sentenac 1991). Upon infection by Erwinia chrysanthemi, the $\mathrm{pH}$ of the plant environment changes because of lysis of plant cells. The $\mathrm{pH}$ influences the expression of distinct pectate lyase genes differentially, resulting in a sequential regulation of virulence gene expression (Nachin and Barras 2000). A tight regulation by environmental factors could explain why fas expression occurs mainly inside the plants, although the required inducers are synthesized by bacteria located on the surface, through the induced att locus.

An observation that adds to the complexity of the regulation of virulence genes during infection is the reduction of att expression in bacteria located inside plant tissues. This reduction suggests the involvement of a regulatory mechanism that renders the expression of the fas and att loci mutually exclusive. A positive regulatory feedback loop of the fas locus that controls its own expression, additional inducer compounds, or both could guarantee continued expression of the fas locus in plant tissues when att expression is absent. This hypothesis is supported by our observation that in an attR mutant strain, which no longer produces inducing compounds, the fas genes are expressed at later stages of the infection, namely after bacteria have penetrated the plant tissues. Delayed fas expression in the absence of an intact att locus could also account for the attenuated leafy gall formation in att mutant bacteria (Crespi et al. 1992; Maes et al. 2001). In Ralstonia solanacearum, the hrp secretion machinery can be induced by plant-derived signals or by signals that reflect the nutritional status of the bacteria. Abolishing one signal-transduction pathway does not render the bacteria nonpathogenic (Brito et al. 1999; Vasse et al. 2000). Similarly, the fas locus of $R$. fascians can be expressed, albeit less efficiently, in a plant environment when the attderived inducers are absent.

In conclusion, our results indicate that site-specific conditions are involved in the induced expression of the fas and att loci. The expression of both loci is associated with sites of meristematic activity and symptom development, but they present spatial and temporal differences. The att-controlled inducer compounds must be part of a more complex regulatory network in which other factors influence the up and down regulation of the fas and att genes.

\section{MATERIALS AND METHODS}

\section{Bacterial strains, plants, and infection methods.}

The bacterial strains $R$. fascians D188 (Desomer et al. 1992) and D188 $\Delta a t t R$ (Maes et al. 2001) were transformed with the plasmids listed in Table 1. $R$. fascians strains were grown for 2 days in yeast extract broth medium at $28^{\circ} \mathrm{C}$ (Miller 1972). $N$. tabacum W38 seedlings were cultured on solid Murashige and Skoog basal mineral medium supplemented with $1 \%$ sucrose (Murashige and Skoog 1962). Infections were done by dipping 4-week-old plants in late-exponential, 2-day-old bacterial cultures (Cornelis et al. 2001).

\section{Histochemical GUS assays.}

Plant material was treated as described by D'Haeze and colleagues (1998). After the GUS reaction, samples were fixed in $2.5 \%$ glutaraldehyde in $0.1 \mathrm{M}$ phosphate buffer $(\mathrm{pH} 7.2)$ and dehydrated with ethanol. GUS activity in different plant parts was scored and calculated as the percentage of the GUS-positive score on the total number of plants screened per time point and construct. The results were analyzed with Statistica software (StatSoft, Tulsa, OK, U.S.A.).

Plant parts that showed GUS activity were embedded in Technovit 7100 (Hereaus-Kulzer, Wehrheim, Germany). The samples were cut into 2- to 3- $\mu \mathrm{m}$ sections with a microtome (Reichert-Jung, Nussloch, Germany) and mounted on silanecoated slides (CEL Associates Inc., Houston, TX, U.S.A.). Selected sections were stained with $0.5 \%$ toluidine blue for morphological analysis (D'Haeze et al. 1998), air-dried, and mounted in Depex mounting medium (BDH, Poole, U.K.). GUS staining was observed with a Diaplan microscope (Leitz, Wetzlar, Germany) with dark-field optics. The semiadjacent sections stained with toluidine blue were observed through bright-field optics.

\section{Quantification of GUS activity.}

Plants were harvested at distinct time points after infection. Of each plant, the lower and upper leaves and the second axil were crushed in extraction buffer (Jefferson et al. 1987) that consisted of $50 \mathrm{mM}$ sodium phosphate, $10 \mathrm{mM} \mathrm{Na}_{2}$-ethylenediaminetetraacetic acid, and 0.1\% Triton X-100 (Sigma-Aldrich, St. Louis, MO, U.S.A.) at $\mathrm{pH}$ 7.0. The extracts were used at different dilutions for GUS assays and for determination of CFU. Reactions were performed in extraction buffer, with $2 \mathrm{mM}$ methylumbelliferone glucuronide as a substrate, and measured with a kinetic program for 150 min with Fluoroscan II (Labsystems Inc., Helsinki, Finland) and Genesis software (Labsystems Inc.). Activity was expressed as the maximal fluorescence increase per min and per CFU and multiplied by $10^{7}$ for ease of statistical manipulation. For statistics, variance analysis with the Statistica program (StatSoft) was used. Because no significant differences were observed between the leaves of different sites on the plants, they were treated subsequently as one group.

\section{Immunolocalization of $\boldsymbol{R}$. fascians in sections and extracts.}

A polyclonal antibody was obtained from the Holland Bulb Center (Lisse, The Netherlands) as serum of rabbits immunized with heat-killed $R$. fascians cells. To reduce the background signal, the antibody was preabsorbed with dried plant extract as described by Bauwens and colleagues (1997). The IL assay was as described by De Wilde and colleagues (1998), with a 
fluorescein isothiocyanate isomer I-conjugated secondary antibody, which was detected as a green signal with an Axioskop fluorescence microscope (Zeiss, Jena, Germany), with an excitation filter (DBP 486/15 and 587/14) and a beam splitter (FT 500/600) with barrier filters (BP 515/40 and LP 610).

Three weeks after infection, plants were harvested and the extracts were examined by IL. Infected plants were extracted as such or first subjected to surface sterilization with $6 \%$ bleach solution for $1 \mathrm{~min}$, followed by two washes with sterile water. Plants were crushed with a pestle and extracted with sterile water. The extracts were clarified by centrifugation, applied to slides, and air-dried. Slides with extracts were fixed and further treated for IL as plant material. The DNA was stained with DAPI (Sigma-Aldrich). The extracts of each plant were examined separately, and 300 DAPI-stained cells of each extract were examined for their immunofluorescence signal. Alternatively, a slide with extract was first used for ISH to detect $R$. fascians (Cornelis et al. 2001) and then subjected to the IL procedure.

\section{ACKNOWLEDGMENTS}

The authors are grateful to D. Vereecke and T. Ritsema for helpful encouragements with the manuscript and M. De Cock for help in preparing it. This work was supported by a grant from the Interuniversity Poles of Attraction Programme (Belgian State, Prime Minister's Office-Federal Office for Scientific, Technical and Cultural Affairs; P4/15). M. Jaziri is a research associate of the Fonds National de la Recherche Scientifique (FNRS).

\section{LITERATURE CITED}

Bauwens, S., Verhoeyen, E., de Almeida Engler, J., Van Montagu, M., and Engler, G. 1997. Detection of mRNA via fluorescence in situ hybridization and confocal microscopy in whole mounts of roots of Arabidopsis thaliana. Plant Mol. Biol. Rep. 15:22-37.

Brito, B., Marenda, M., Barberis, P., Boucher, C., and Genin, S. 1999. prhJ and $h r p G$, two new components of the plant signal-dependent regulatory cascade controlled by PrhA in Ralstonia solanacearum. Mol. Microbiol. 31:237-251.

Cornelis, K., Ritsema, T., Nijsse, J., Holsters, M., Goethals, K., and Jaziri, M. 2001. The plant pathogen Rhodococcus fascians colonizes the exterior and interior of the aerial parts of plants. Mol. PlantMicrobe Interact. 14:599-608.

Crespi, M., Messens, E., Caplan, A. B., Van Montagu, M., and Desomer, J. 1992. Fasciation induction by the phytopathogen Rhodococcus fascians depends upon a linear plasmid encoding a cytokinin synthase gene. EMBO (Eur. Mol. Biol. Organ.) J. 11:795-804.

Crespi, M., Vereecke, D., Temmerman, W., Van Montagu, M., and Desomer, J. 1994. The fas operon of Rhodococcus fascians encodes new genes required for efficient fasciation of host plants. J. Bacteriol. 176:2492-2501.

de O. Manes, C.-L., Van Montagu, M., Prinsen, E., Goethals, K., and Holsters, M. 2001. De novo cortical cell division triggered by the phytopathogen Rhodococcus fascians in tobacco. Mol. Plant-Microbe Interact. 14:189-195.

Desomer, J., Vereecke, D., Crespi, M., and Van Montagu, M. 1992. The plasmid-encoded chloramphenicol resistance protein of Rhodococcus fascians is homologous to the transmembrane tetracycline efflux proteins. Mol. Microbiol. 6:2377-2385.
De Wilde, C., De Rycke, R., Beeckman, T., De Neve, M., Van Montagu, M., Engler, G., and Depicker, A. 1998. Accumulation pattern of IgG antibodies and $\mathrm{F}_{\mathrm{ab}}$ fragments in transgenic Arabidopsis thaliana plants. Plant Cell Physiol. 39:639-646.

D’Haeze, W., Gao, M., De Rycke, R., Van Montagu, M., Engler, G., and Holsters, M. 1998. Roles for azorhizobial Nod factors and surface polysaccharides in intercellular invasion and nodule penetration, respectively. Mol. Plant-Microbe Interact. 11:999-1008.

Dunny, G. M., and Leonard, B. A. B. 1997. Cell-cell communication in gram-positive bacteria. Annu. Rev. Microbiol. 51:527-564.

Fuqua, C., Winans, S. C., and Greenberg, P. 1994. Quorum sensing in bacteria: The LuxR-LuxI family of cell density-responsive transcriptional regulators. J. Bacteriol. 176:269-275.

Fuqua, C., Winans, S. C., and Greenberg, E. P. 1996. Census and consensus in bacterial ecosystems: The LuxR-LuxI family of quorum-sensing transcriptional regulators. Annu. Rev. Microbiol. 50:727-751.

Goethals, K., Vereecke, D., Jaziri, M., Van Montagu, M., and Holsters, M. 2001. Leafy gall formation by Rhodococcus fascians. Annu. Rev. Phytopathol. 39:27-52.

Grignon, C., and Sentenac, H. 1991. $\mathrm{pH}$ and ionic conditions in the apoplast. Annu. Rev. Plant Physiol. Plant Mol. Biol. 42:103-128.

Horinouchi, S., and Beppu, T. 1992. Autoregulatory factors and communication in Actinomycetes. Annu. Rev. Microbiol. 46:377-398.

Jefferson, R. A., Kavanagh, T. A., and Bevan, M. W. 1987. GUS fusions: $\beta$-Glucuronidase as a sensitive and versatile gene fusion marker in higher plants. EMBO (Eur. Mol. Biol. Organ.) J. 6:3901-3907.

Kleerebezem, M., Quadri, L. E. N., Kuipers, O. P., and de Vos, W. M. 1997. Quorum sensing by peptide pheromones and two-component signal-transduction systems in Gram-positive bacteria. Mol. Microbiol. 24:895-904.

Maes, T., Vereecke, D., Ritsema, T., Cornelis, K., Thi Thu, H. N., Van Montagu, M., Holsters, M., and Goethals, K. 2001. The att locus of the phytopathogen Rhodococcus fascians D188 is essential for full virulence through the production of an autoregulatory compound. Mol. Microbiol. 42:13-29.

Miller, J. H. 1972. Experiments in Molecular Genetics. Cold Spring Harbor Laboratory Press, Cold Spring Harbor, NY, U.S.A.

Murashige, T., and Skoog, F. 1962. A revised medium for rapid growth and bio assays with tobacco tissue cultures. Physiol. Plant. 15:473497.

Nachin, L., and Barras, F. 2000. External pH: An environmental signal that helps to rationalize pel gene duplication in Erwinia chrysanthemi. Mol. Plant-Microbe Interact. 13:882-886.

Schell, M. A. 2000. Control of virulence and pathogenicity genes of Ralstonia solanacearum by an elaborate sensory network. Annu. Rev. Phytopathol. 38:263-292.

Temmerman, W. 2000. The role of the fas locus in leafy gall formation by Rhodococcus fascians. Ph.D. dissertation. Ghent University, Ghent, Belgium.

Temmerman, W., Vereecke, D., Dreesen, R., Van Montagu, M., Holsters, M., and Goethals, K. 2000. Leafy gall formation is controlled by fasR, an AraC-type regulatory gene, in Rhodococcus fascians. J. Bacteriol. 182:5832-5840.

Teplitski, M., Robinson, J. B., and Bauer, W. D. 2000. Plants secrete substances that mimic bacterial $N$-acyl homoserine lactone signal activities and affect population density-dependent behaviors in associated bacteria. Mol. Plant-Microbe Interact. 13:637-648.

Vasse, J., Genin, S., Frey, P., Boucher, C., and Brito, B. 2000. The hrpB and $h r p G$ regulatory genes of Ralstonia solanacearum are required for different stages of the tomato root infection process. Mol. PlantMicrobe Interact. 13:259-267.

Vereecke, D., Burssens, S., Simón-Mateo, C., Inzé, D., Van Montagu, M., Goethals, K., and Jaziri, M. 2000. The Rhodococcus fascians-plant interaction: Morphological traits and biotechnological applications. Planta 210:241-251. 